\title{
Video Article \\ One-day Workflow Scheme for Bacterial Pathogen Detection and Antimicrobial Resistance Testing from Blood Cultures
}

\author{
Wendy L.J. Hansen ${ }^{1}$, Judith Beuving ${ }^{1}$, Annelies Verbon ${ }^{2}$, Petra. F.G. Wolffs ${ }^{1}$ \\ ${ }^{1}$ Department of Medical Microbiology, Maastricht University Medical Center \\ ${ }^{2}$ Department of Internal Medicine, Erasmus Medical Center
}

Correspondence to: Petra. F.G. Wolffs at p.wolffs@mumc.nl

URL: https://www.jove.com/video/3254

DOI: doi: $10.3791 / 3254$

Keywords: Immunology, Issue 65, Infection, Medicine, Microbiology, Bacteria, real-time PCR, probes, pathogen detection, blood culture, 16S rDNA gene, antibiotic resistance, antibiotic susceptibility testing

Date Published: 7/9/2012

Citation: Hansen, W.L., Beuving, J., Verbon, A., Wolffs, P.F. One-day Workflow Scheme for Bacterial Pathogen Detection and Antimicrobial Resistance Testing from Blood Cultures. J. Vis. Exp. (65), e3254, doi:10.3791/3254 (2012).

\section{Abstract}

Bloodstream infections are associated with high mortality rates because of the probable manifestation of sepsis, severe sepsis and septic shock $^{1}$. Therefore, rapid administration of adequate antibiotic therapy is of foremost importance in the treatment of bloodstream infections. The critical element in this process is timing, heavily dependent on the results of bacterial identification and antibiotic susceptibility testing. Both of these parameters are routinely obtained by culture-based testing, which is time-consuming and takes on average $24-48$ hours ${ }^{2,4}$. The aim of the study was to develop DNA-based assays for rapid identification of bloodstream infections, as well as rapid antimicrobial susceptibility testing. The first assay is a eubacterial $16 \mathrm{~S}$ rDNA-based real-time PCR assay complemented with species- or genus-specific probes ${ }^{5}$. Using these probes, Gram-negative bacteria including Pseudomonas spp., Pseudomonas aeruginosa and Escherichia coli as well as Gram-positive bacteria including Staphylococcus spp., Staphylococcus aureus, Enterococcus spp., Streptococcus spp., and Streptococcus pneumoniae could be distinguished. Using this multiprobe assay, a first identification of the causative micro-organism was given after $2 \mathrm{~h}$.

Secondly, we developed a semi-molecular assay for antibiotic susceptibility testing of $S$. aureus, Enterococcus spp. and (facultative) aerobe Gram-negative rods ${ }^{6}$. This assay was based on a study in which PCR was used to measure the growth of bacteria ${ }^{7}$. Bacteria harvested directly from blood cultures are incubated for $6 \mathrm{~h}$ with a selection of antibiotics, and following a Sybr Green-based real-time PCR assay determines inhibition of growth. The combination of these two methods could direct the choice of a suitable antibiotic therapy on the same day (Figure 1). In conclusion, molecular analysis of both identification and antibiotic susceptibility offers a faster alternative for pathogen detection and could improve the diagnosis of bloodstream infections.

\section{Video Link}

The video component of this article can be found at https://www.jove.com/video/3254/

\section{Protocol}

\section{PART I: PATHOGEN IDENTIFICATION}

\section{Sample Preparation}

Note: The entire molecular workflow as is described in the following protocol should be performed according to recommendations for quality assurance in molecular diagnostics ${ }^{3}$.

1. Add an $0.1 \mathrm{ml}$ aliquot of blood culture to $0.9 \mathrm{ml} 0.9 \% \mathrm{NaCl}$ into a $1.5 \mathrm{ml}$ reaction tube to become a $1: 10$ diluted sample. (Dilute in order to prevent qPCR inhibition)

2. Centrifuge sample at $13400 \times \mathrm{g}$ for $5 \mathrm{~min}$ to pellet the bacterial DNA.

3. Resuspend the bacterial pellet in $100 \mu$ sterile demineralised $\mathrm{H}_{2} \mathrm{O}$.

4. Store the DNA sample at $4{ }^{\circ} \mathrm{C}$ until further use.

\section{Identification Assay: Real-time 16s rDNA PCR}

1. Prepare the reaction mixtures as follows. The assay consists of four separate reactions per sample. Each mixture includes $12.50 \mu \mathrm{l}$ master mix, $0.9 \mu \mathrm{M}$ forward primer (5-TCCTACGGGAGGCAGCAGT-3) $)^{7}, 0.6 \mu \mathrm{M}$ reverse primer (5-GGACTACCAGGGTATCTAATCCTGTT-3) ${ }^{8}$ and a panel of probes. The amount of probes is given for each of the four separate reactions in below.

2. The first reaction includes:

$$
\text { - } \quad 0.2 \mu \mathrm{M} \text { universal probe (5-FAM-CGTATTACCGCGGCTGCTGGCAC-3-BHQ1) }{ }^{8}
$$


- $\quad 0.2 \mu \mathrm{M}$ P. aeruginosa probe (5-JOE-CCAAAACTACTGAGCTAGAGTACG-3-BHQ1)

3. The second reaction includes:

- $\quad 0.2 \mu \mathrm{M}$ E. coli probe (5-JOE-GGAGTAAAGTTAATACCTTTGCTCATT-3-BHQ1)

- $\quad 0.2 \mu \mathrm{M}$ Pseudomonas spp. probe (5-NED-CCTTCCTCCCAACTTAAAGTGCTT-3-MGBNFQ)

4. The third reaction includes:

- $\quad 0.2 \mu \mathrm{M}$ Staphylococcus spp. probe (5-NED-AATCTTCCGCAATGGGCGAAAGC-3-MGBNFQ)

- $\quad 0.2 \mu \mathrm{M}$ S. aureus probe (5-FAM-AGATGTGCACAGTTACTTACACATAT-3-BHQ1)

- $0.2 \mu \mathrm{M}$ Enterococcus spp. (5-JOE-TCCTTGTTCTTCTCTAACAACAGAG-3-BHQ1)

5. The fourth reaction includes:

- $0.2 \mu \mathrm{M}$ universal probe (5-FAM-CGTATTACCGCGGCTGCTGGCAC-3-BHQ1)

- $0.3 \mu \mathrm{M}$ Streptococcus spp. probe (5-NED-CCAGAAAGGGACSGCTAACT-3-MGBNFQ)

- $0.2 \mu \mathrm{M}$ S. pneumoniae probe (5-JOE-CCAAAGCCTACTATGGTTAAGCCA-3-BHQ1)

6. Add sterile demineralised $\mathrm{H}_{2} \mathrm{O}$ to reach a total volume of $20 \mu \mathrm{l}$. Add $20 \mu \mathrm{l}$ of each reaction mixture to the wells of a 96-well PCR plate.

7. Add $5 \mu \mathrm{l}$ of sample to each well.

8. Use an adhesive film to seal the 96-well PCR plate.

9. Run the plate on the ABI PRISM 7900HT Real Time PCR System using the following optimal thermal cycling conditions:

- Pre-heating at $50{ }^{\circ} \mathrm{C}$ for $10 \mathrm{~min}$

- Initial denaturation at $95^{\circ} \mathrm{C}$ for $15 \mathrm{~min}$

- 42 cycles of

- Denaturation at $95^{\circ} \mathrm{C}$ for $15 \mathrm{~s}$

- Annealing at $60^{\circ} \mathrm{C}$ for $1 \mathrm{~min}$

\section{Analysis of the Results}

1. Adjust the threshold of the Ct Analysis to 0.1 in the tab Analysis Settings. Narrow the baseline configurations to Start (Cycle):6 and End (Cycle): 15.

2. Record the cycle threshold $(\mathrm{Ct})$ value for all samples. The cut-off value to consider a PCR result as positive can be set to a Ct-value of 35 . The amount of bacteria present in blood cultures ranged from $10^{7}$ to $10^{11} \mathrm{CFU} / \mathrm{ml}$, generating Ct-values below 35 .

\section{PART II: ANTIBIOTIC SUSCEPTIBILITY TESTING}

\section{Isolation of Bacteria from Positive Blood Cultures ${ }^{9}$}

1. Aspirate $5 \mathrm{ml}$ of broth from a positive blood culture bottle and transfer it into a serum separator tube.

2. Centrifuge the serum separator tube at $2000 \mathrm{xg}$ for $10 \mathrm{~min}$.

3. Discard the supernatant from the serum separator tube.

4. Transfer bacteria from the gel layer of the tube with a sterile cotton swab into $0.9 \%$ saline until a 0.5 McFarland standard suspension is obtained.

\section{Inoculation of Micro Titre Plates}

1. Dilute the $0.5 \mathrm{McF}$ arland suspension in double concentrated Mueller Hinton II broth to form a suspension of $5 \times 10^{5} \mathrm{CFU} / \mathrm{ml}$.

2. Add this suspension to the wells of a micro titre plate containing a selection of antibiotics (Table 1).

3. Incubate the micro titre plate at $37^{\circ} \mathrm{C}$ for $6 \mathrm{~h}$.

4. Store an aliquot of the suspension at $4{ }^{\circ} \mathrm{C}$ (as negative growth control).

5. After $6 \mathrm{~h}$ of incubation, transfer the content of each well into a sterile tube, as well as the negative growth control sample that was stored at 4 ${ }^{\circ} \mathrm{C}$.

6. Centrifuge the tubes at $16000 \times \mathrm{g}$ for $5 \mathrm{~min}$.

7. Carefully remove the supernatant, without disturbing the bacterial pellet.

8. Resuspend the pellet in sterile demineralised $\mathrm{H}_{2} \mathrm{O}$.

9. Dilute the samples 10 -fold in sterile demineralised $\mathrm{H}_{2} \mathrm{O}$.

\section{Real-time 16s rDNA PCR ${ }^{10}$}

1. Prepare the PCR mixture as follows:

- $12.50 \mu \mathrm{l}$ iQ SYBR Green Supermix

- $0.5 \mu \mathrm{M}$ forward primer 16S-1 (5-TGGAGAGTTTGATCCTGGCTCAG-3) ${ }^{11}$

- $0.25 \mu \mathrm{M}$ reverse primer 16S-2 (5-TACCGCGGCTGCTGGCAC-3) ${ }^{11}$

- sterile demineralised $\mathrm{H}_{2} \mathrm{O}$ to a total volume of $20 \mu \mathrm{l}$

2. Add $20 \mu$ l of PCR mixture to the wells of a 96-well PCR plate.

3. Add $5 \mu \mathrm{l}$ of sample to each well.

4. Use an adhesive film to seal the 96-well PCR plate. 
5. Run the plate on the MyiQ Single-Color Real-Time PCR Detection System, using the following optimal thermal cycling conditions:

- Initial denaturation at $95^{\circ} \mathrm{C}$ for 4 min

- Initial annealing at $65^{\circ} \mathrm{C}$ for $30 \mathrm{~s}$

- 35 cycles of

- Denaturation at $95^{\circ} \mathrm{C}$ for $15 \mathrm{~s}$

- Annealing at $60^{\circ} \mathrm{C}$ for $1 \mathrm{~min}$

- Melt curve analysis (from $60-95^{\circ} \mathrm{C}$ in 20 min with increments of $0.57^{\circ} \mathrm{C}$ )

\section{Analysis of the Results}

1. Calculate the cut-off $\mathrm{Ct}$ value using one of the following formulas (depending on type of antibiotic).

- In general:

Cut-off Ct value $=C t$ value positive growth control $+0.5 \times$ (Ct value negative growth control - Ct value positive growth control)

- Piperacillin, piperacillin/tazobactam and ceftazidime in Gram-negative rods; Amoxicillin, oxacillin and trimethoprim/sulfamethoxazole in S.aureus; Amoxicillin in Enterococcus spp.: Cut-off Ct value $=$ Ct value positive growth control $+0.25 \times$ (Ct value negative growth control - Ct value positive growth control)

2. Use the sample incubated with sterile demineralised $\mathrm{H}_{2} \mathrm{O}$ as positive growth control.

3. Depending on the microorganism, use the appropriate negative growth control:

- Gram-negative rods Sample incubated with mixture of antibiotics

- Enterococcus spp. Sample stored at $4{ }^{\circ} \mathrm{C}$

- S.aureus Sample stored at $4{ }^{\circ} \mathrm{C}$

4. Determine the susceptibility $(S)$ or resistance $(R)$ of the strain for the tested antibiotic as follows:

- A Ct value higher than the cut-off Ct value indicates susceptibility

- A Ct value lower than the cut-off $\mathrm{Ct}$ value indicates resistance

\section{Representative Results}

Two model organisms, i.e. a Gram-negative E. coli and a Gram-positive S. aureus, are chosen to visualize the combined procedure for the detection and identification of bacterial pathogens and the determination of their antimicrobial profile. The first part of the protocol comprises the pathogen identification. Specific probes are designed for the detection of eight clinically relevant microorganisms. In presence of a target included in the bacterial panel, amplification curves are generated and Ct values are calculated (Figure 2). The cut-off value to consider a PCR result as positive is set to a Ct value of 35 . In Figure $\mathbf{2 A}$, the identification profile of an E.coli-infected blood culture is shown. The $16 \mathrm{~S}$ universal probe is included in two separate reaction mixtures and consequently generates two amplification curves (Ct of 25.20 and 25.95). The third signal is derived from the probe specific for $E$. coli (Ct of 27.04). The identification of a S. aureus-infected blood culture is shown in Figure 2B. The $16 \mathrm{~S}$ universal probe has amplification signals of 33.35 and 33.71 . The two remaining signals are derived from the probes specific for Staphylococcus spp. and S. aureus (Ct of 32.48 and 30.59).

After the first part of the protocol, the causative microorganism is known and the antimicrobial profile can be determined. Figure 3 is an example of an antibiotic susceptibility testing amplification plot, representing the E.coli strain that was also shown in Figure 2A. Each line represents one antibiotic that the bacterial sample was incubated with. A sample with a low Ct value is a sample in which growth has occurred in the presence of an antibiotic, indicating resistance to the tested antibiotic. On the contrary, a high Ct value represents a sample in which no growth has occurred because of the effective working of the antibiotic, indicating susceptibility to the tested antibiotic. Table 1 illustrates the determination of the antimicrobial profile of the E. coli and S. aureus isolates. All Ct values are reported and, using the formulas mentioned in the protocol text (7.1), two cut-off $\mathrm{Ct}$ values are calculated to distinguish between resistance and susceptibility. The strain is resistant to the antibiotic if the reported $\mathrm{Ct}$ value is lower than the calculated cut-off $\mathrm{Ct}$ value (and vice versa). 
P1

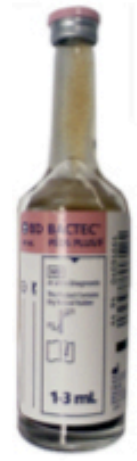

\section{Step 1: Pathogen identification - 2 hours}

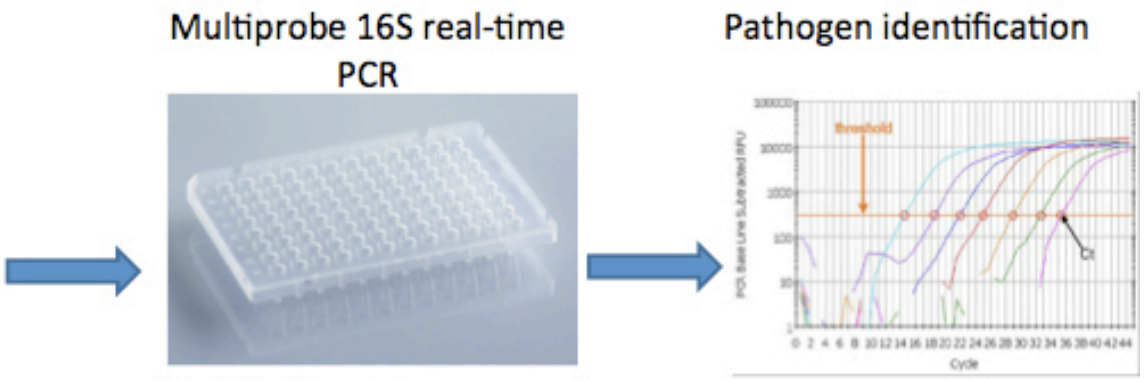

- Staphylococcus spp.

- S. aureus

- Enterococcus spp.

- Streptococcus spp.

- S. pneumoniae

- E. coli

- Pseudomonas spp.

- $P$. aeruginosa

Figure 1. Flow chart of the pathogen identification and antibiotic susceptibility testing procedure using real-time $16 S$ rDNA PCR.

A

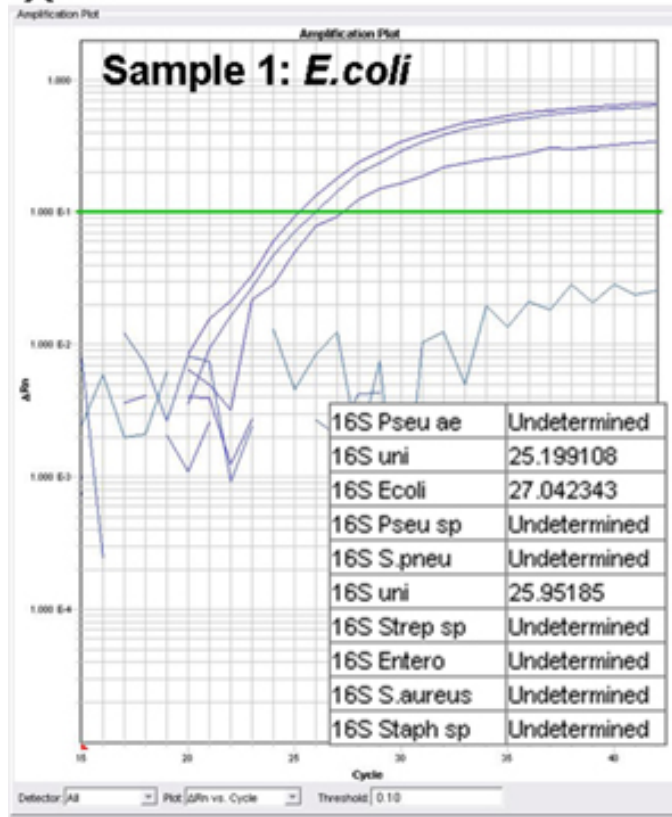

B

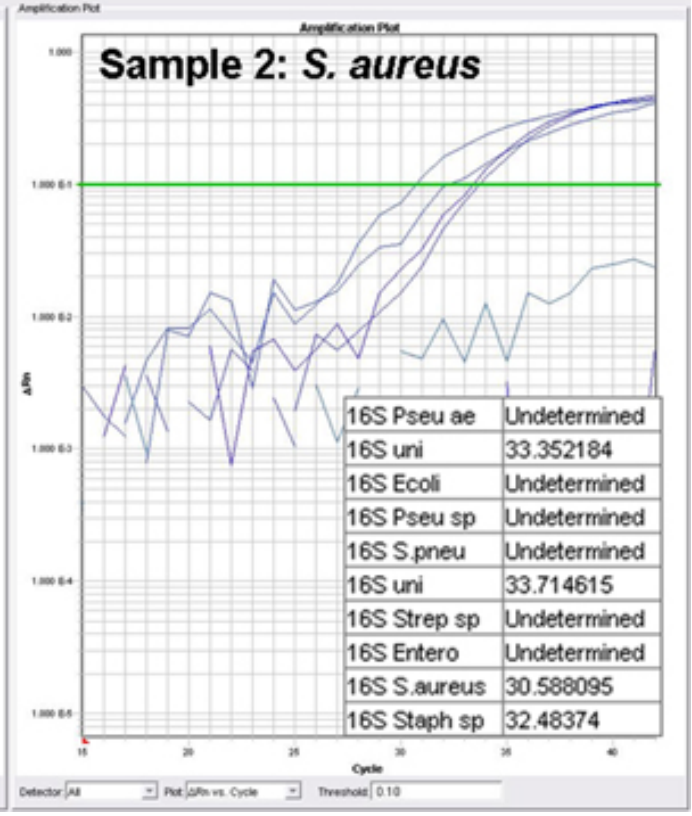

Figure 2. Identification assay: Amplification plots and cycle threshold values (Ct values). A positive blood culture is detected by the universal $16 \mathrm{~S}$ rDNA probe, while the specific probes are used for the identification of the causal pathogen. A. amplification plot of blood culture containing E. coli; B. amplification plot of blood culture containing S. aureus; Pseu ae, Pseudomonas aeruginosa; uni, 16S universal probe; Ecoli, Escherichia coli probe; Pseu sp, Pseudomonas spp. probe; S. pneu, Streptococcus pneumoniae probe; Strep sp, Streptococcus spp. probe; Entero, Enterococcus spp. probe; S. aureus, Staphylococcus aureus probe; Staph sp, Staphylococcus spp. probe. 


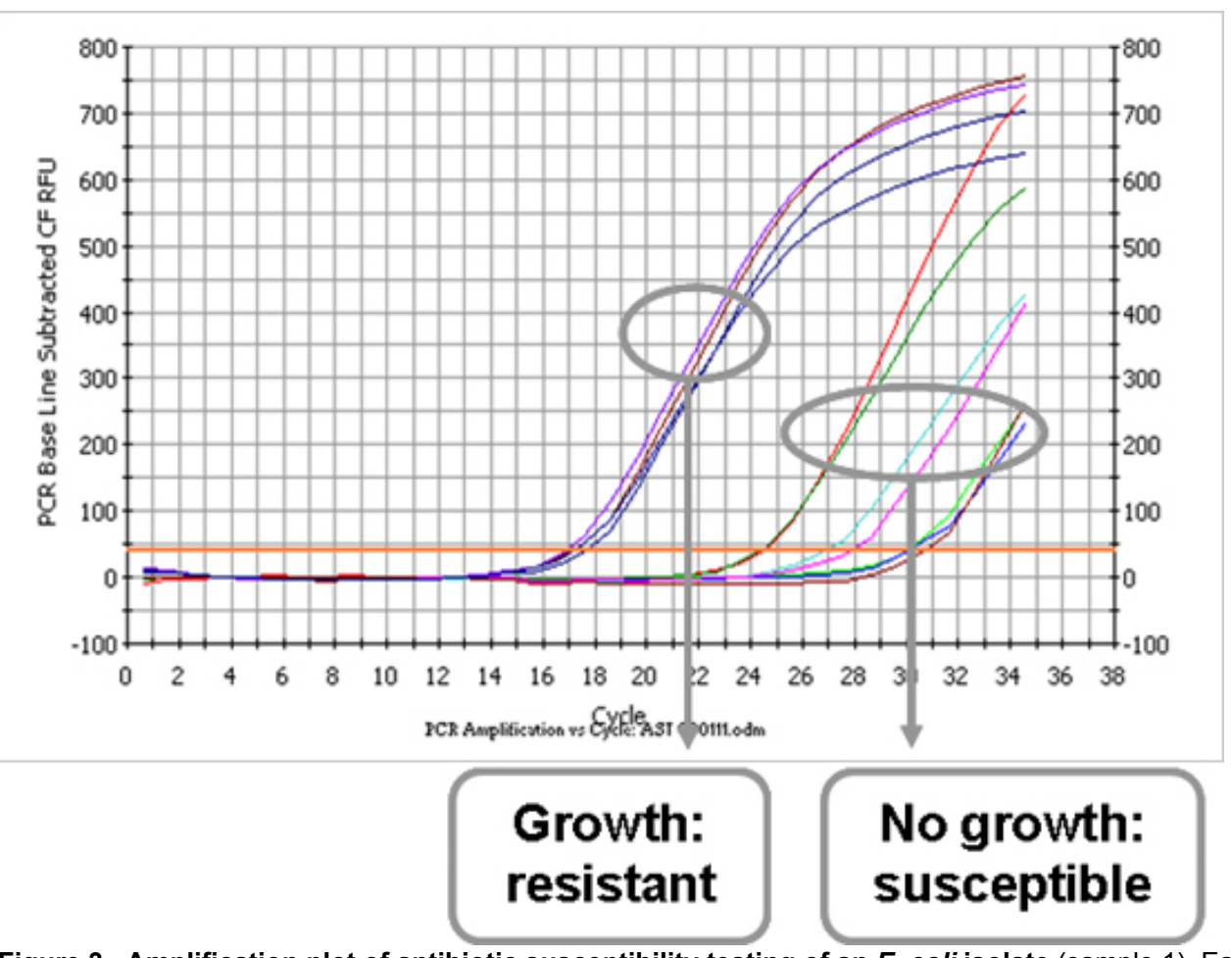

Figure 3. Amplification plot of antibiotic susceptibility testing of an E. coli isolate (sample 1). Each curve represents one antibiotic that the strain was incubated with. An early signal is caused by a high bacterial load, which means that the strain has grown in the presence of the tested antibiotic and is thus resistant to the antibiotic. Late signals indicate that the strain has not grown in the presence of the antibiotic, in other words, it is susceptible.

\begin{tabular}{|c|c|c|c|c|c|}
\hline Sample 1: E. coli & & & Sample 2: S. aureus & & \\
\hline AST & $\mathbf{C t}$ & $R / S$ & AST & $\mathbf{C t}$ & $R / S$ \\
\hline Amoxicillin $8 \mathrm{mg} / \mathrm{L}$ & 16,83 & $\mathbf{R}$ & Amoxicillin $0.25 \mathrm{mg} / \mathrm{L}$ & 21,03 & $\mathbf{R}$ \\
\hline $\begin{array}{l}\text { Amoxicillin-clavulanate } \\
8 / 4 \mathrm{mg} / \mathrm{L}\end{array}$ & 17,36 & $\mathbf{R}$ & Oxacillin $2 \mathrm{mg} / \mathrm{L}$ & 25,80 & $S$ \\
\hline Piperacillin 16 mg/L & 16,67 & $\mathbf{R}$ & Vancomycin $2 \mathrm{mg} / \mathrm{L}$ & 25,20 & $S$ \\
\hline $\begin{array}{l}\text { Piperacillin- } \\
\text { tazobactam } 16 / 4 \mathrm{mg} / \mathrm{L}\end{array}$ & 24,15 & s & Gentamicin $4 \mathrm{mg} / \mathrm{L}$ & 25,86 & $\mathbf{S}$ \\
\hline Ciprofloxacin $1 \mathrm{mg} / \mathrm{L}$ & 29,72 & S & $\begin{array}{l}\text { Trimethoprim- } \\
\text { sulfamethoxazole 2/38 } \\
\mathrm{mg} / \mathrm{L}\end{array}$ & 24,62 & $\mathbf{S}$ \\
\hline Ceftazidime $1 \mathrm{mg} / \mathrm{L}$ & 24,03 & S & & & \\
\hline Ceftazidime $8 \mathrm{mg} / \mathrm{L}$ & 26,58 & $S$ & & & \\
\hline Gentamicin 4 mg/L & 29,83 & $S$ & & & \\
\hline $\begin{array}{l}\text { Trimethoprim- } \\
\text { sulfamethoxazole } 2 / 38 \\
\mathrm{mg} / \mathrm{L}\end{array}$ & 27,60 & $\mathrm{~s}$ & & & \\
\hline $\begin{array}{l}\text { Negative growth } \\
\text { control (mixture of } \\
\text { antibiotics) }\end{array}$ & 30,41 & & $\begin{array}{l}\text { Negative growth } \\
\text { control (sample stored } \\
\text { at } 4{ }^{\circ} \mathrm{C} \text { ) }\end{array}$ & 27,42 & \\
\hline Positive growth control & 16,90 & & Positive growth control & 20,22 & \\
\hline Cut-off Ct-value $1^{*}$ & 21,76 & & Cut-off Ct-value $1^{* * *}$ & 23,82 & \\
\hline Cut-off Ct-value $2^{* *}$ & 18,75 & & Cut-off Ct-value $2^{\star \star * \star}$ & 22,02 & \\
\hline $\begin{array}{l}{ }^{*} \text { For amoxicillin, } \\
\text { amoxicillin- }\end{array}$ & & & $\begin{array}{l}{ }^{* * *} \text { For vancomycin } \\
\text { and gentamicin }\end{array}$ & & \\
\hline
\end{tabular}




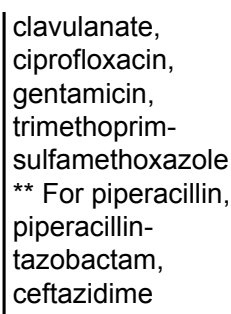

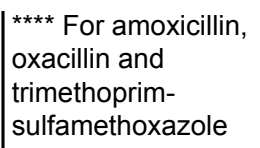

Table 1. Determination of antibiotic susceptibility testing of the two samples (E.coli and S.aureus). Ct values of the PCR-assay were copied to this excel file, as which can automatically calculates the two cut-off Ct alues from the positive and negative growth control, using the formulas shown in the protocol text. If an antibiotic shows a Ct value lower than the cut-off Ct value, the strain is resistant to the antibiotic, if the Ct value was higher than the cut-off, the strain is susceptible.

\section{Discussion}

The protocol described here enables the rapid identification of pathogens and provides a functional antimicrobial profile that could lead to the early administration of adequate antibiotics thereby improving the prognosis of patients with bloodstream infections. Depending on the requested conditions of a test, i.e. low cost, high throughput, minimal turn-around time, testing conditions can be adjusted. The whole procedure can be performed within one working day. Moreover, the two parts of the protocol can be performed simultaneously, which reduces the turn-around time significantly. As presented here, the identification panel is a selection of the most clinically relevant bacteria in our hospital. Since the main principle is targeting the $16 \mathrm{~S}$ gene region, specific probes for other microorganisms can be designed and added to the assay. The complete assay was originally intended for the rapid analysis of blood cultures, but can also be used for the processing of other sample materials. This is also the case for the antibiotics that were used for antibiotic susceptibility testing: more or other antibiotics can be added, based on local resistance patterns and guidelines.

\section{Disclosures}

We have nothing to disclose.

\section{Acknowledgements}

This work was supported by the Profileringsfonds azM (PF245).

\section{References}

1. Wallet, F., et al. Preliminary clinical study using a multiplex real-time PCR test for the detection of bacterial and fungal DNA directly in blood. Clin. Microbiol. Infect. 16 (6), 774 (2010).

2. Beekmann, S.E., Diekema, D.J., Chapin, K.C., \& Doern, G.V. Effects of rapid detection of bloodstream infections on length of hospitalization and hospital charges. J. Clin. Microbiol. 41 (7), 3119 (2003).

3. Raymaekers, M., Bakkus, M., Boone, E., de Rijke, B., El Housni, H., Descheemaeker, P., De Schouwer, P., Franke, S., Hillen, F., Nollet, F., Soetens, O., Vankeerberghen, A. Molecular Diagnostics working group. Reflections and proposals to assure quality in molecular diagnostics. Acta. Clin. Belg. 66 (1), 33 (2011).

4. Peters, R.P., et al. New developments in the diagnosis of bloodstream infections. Lancet Infect. Dis. 4 (12), 751 (2004).

5. Hansen, W.L., Beuving, J., Bruggeman, C.A., \& Wolffs, P.F. Molecular probes for the diagnosis of clinically relevant bacterial infections in blood cultures. J. Clin. Microbiol. 48 (12), 4432 (2010).

6. Beuving, J., et al. Antibiotic susceptibility testing of grown blood cultures by combining culture and real-time polymerase chain reaction is rapid and effective. PLoS ONE. 6 (12), (2011).

7. Rolain, J.M., Mallet, M.N., Fournier, P.E., \& Raoult, D. Real-time PCR for universal antibiotic susceptibility testing. J. Antimicrob. Chemother. 54 (2), 538 (2004).

8. Nadkarni, M.A., Martin, F.E., Jacques, N.A., \& Hunter, N. Determination of bacterial load by real-time PCR using a broad-range (universal) probe and primers set. Microbiol. 148 (Pt 1), 257 (2002).

9. Waites, K.B., Brookings, E.S., Moser, S.A., \& Zimmer, B.L. Direct susceptibility testing with positive BacT/Alert blood cultures by using MicroScan overnight and rapid panels. J. Clin. Microbiol. 36 (7), 2052 (1998).

10. Vliegen, I., et al. Rapid identification of bacteria by real-time amplification and sequencing of the $16 \mathrm{~S}$ rRNA gene. J. Microbiol. Meth. 66 (1), 156 (2006).

11. Hall, L., Doerr, K.A., Wohlfiel, S.L., \& Roberts, G.D. Evaluation of the MicroSeq system for identification of mycobacteria by $16 S$ ribosomal DNA sequencing and its integration into a routine clinical mycobacteriology laboratory. J. Clin. Microbiol. 41 (4), 1447 (2003). 